

\title{
The InSight Blind Test: An Opportunity to Bring a Research Dataset into Teaching Programs
}

Julien Balestra, Jean-Luc Berenguer, Florence Bigot-cormier, Françoise

Courboulex, Lucie Rolland, David Ambrois, Martin van Driel, Philippe

Lognonne

\section{To cite this version:}

Julien Balestra, Jean-Luc Berenguer, Florence Bigot-cormier, Françoise Courboulex, Lucie Rolland, et al.. The InSight Blind Test: An Opportunity to Bring a Research Dataset into Teaching Programs. Seismological Research Letters, 2020, 91 (2A), pp.1064-1073. 10.1785/0220190137 . hal-02461538

\section{HAL Id: hal-02461538 \\ https://hal.science/hal-02461538}

Submitted on 24 Nov 2020

HAL is a multi-disciplinary open access archive for the deposit and dissemination of scientific research documents, whether they are published or not. The documents may come from teaching and research institutions in France or abroad, or from public or private research centers.
L'archive ouverte pluridisciplinaire HAL, est destinée au dépôt et à la diffusion de documents scientifiques de niveau recherche, publiés ou non, émanant des établissements d'enseignement et de recherche français ou étrangers, des laboratoires publics ou privés. 
2 Programs

4 Julien Balestra ${ }^{(1)}$, Jean-Luc Berenguer ${ }^{(2,3)}$, Florence Bigot-Cormier ${ }^{(4)}$, Françoise Courboulex ${ }^{(2)}$, $5 \quad$ Lucie Rolland ${ }^{(2)}$, David Ambrois ${ }^{(2)}$, Martin Van Driel $^{(5)}$ and Philippe Lognonné(6)

7 1) Université Côte d'Azur, Campus Valrose, Bâtiment L, 28 Avenue de Valrose, 06108 Nice 8 CEDEX 2, France

9

2) Université Côte d'Azur, CNRS, Observatoire de la Côte d'Azur, IRD, Géoazur, UMR7329, 250 rue Albert Einstein, Sophia Antipolis 06560 Valbonne, France

3) Centre International De Valbonne, BP 97, 06902 Sophia Antipolis, Cedex, France

4) French School of Shanghai, 350 Gao Guang Road, Qingpu District, Shanghai 201702, China

5) Institute of Geophysics, ETH Zürich, Sonneggstrasse 5, 8092, Zurich, Switzerland

6) Université de Paris, Institut de physique du globe de Paris, CNRS, F-75005 Paris, France

Corresponding author: julien.balestra@univ-cotedazur.fr 
On November 26, 2019, SEIS, the first broadband seismometer designed for the Martian environment (Lognonné et al., 2019) landed on Mars thanks to NASA's InSight mission. On April 6, 2019 (sol 128), the InSight Science team detected the first historical "marsquake" (NASA news release). Before it was recorded, the InSight Science team developed the InSight Blind Test (hereafter IBT), which consists of a 12-month period of continuous waveform data combining realistic estimates of martian background seismic noise, 204 tectonic and 35 impact events (Clinton et al., 2017). This project was originally designed to prepare scientists for the arrival of real data from the upcoming InSight mission. This paper presents the work carried out by middle and high school students during this challenge. This project offered schools the opportunity to participate in and strengthen the link between secondary schools and universities. The IBT organizers accepted the approach to enable fourteen schools to take part in this scientific challenge. After a training process, each school analyzed the IBT dataset to contribute to the collaborative School Team catalog. The schools relied on a manual procedure combining analyses in time and frequency domains. At the end, a combined catalog was submitted as one of the IBT entries. The IBT organizers then assessed the catalog submitted by the consortium of schools together with the results from science teams (Van Driel et al., 2019). The schools achieved a total of 15 correct detections over a short period. While this number may seem modest compared with the 239 synthetic marsquakes included in the IBT waveform data, these correct detections were entirely made during class time. All in all, the students seemed to be fully engaged, and this exercise seemed to increase their scientific inquiry skills in order to fulfill their task as a team. 


\section{Introduction}

The InSight mission includes an education and outreach program $(\mathrm{E} \& \mathrm{O})$ in each partner country. In France, the E\&O is carried out by the Géoazur education team. Many pedagogical resources were proposed for this mission, including aspects from launch to landing. The IBT was an excellent opportunity to prepare students to work on future Martian seismograms. The organizers prepared a synthetic dataset of continuous waveforms and invited participants to detect both tectonic and impact seismicity, along with different sources of noise (Murdoch et al., 2017a, 2017b, Kenda et al., 2017). Note that:

- the IBT stopped on February 2018,

- the continuous synthetic signal was considered for a fictional year 2019 (from January 1 to December 31).

All mentions of data from 2019 concern this fictional year.

The objective was to prepare research teams interested in developing detection procedures and assess the quality of their work by comparing the seismicity catalog they produced with the IBT synthetic seismicity catalog.

Given that using data in schools from scientific research has shown a positive impact on students (Zollo et al., 2014, Bigot-Cormier and Berenguer, 2017), we asked the IBT organizers if the participation of schools was possible. We proposed having the students determine key event parameters such as date, arrival time of seismic waves, epicentral distance and backazimuth direction, terms used in the French educational curriculum. The organizers accepted this format. The School Team was composed of 14 schools either in France or abroad (Fig. 1), all of which are part of the French educational seismic network (Courboulex et al., 2012). Catts Pressoir Middle School is a Haitian school, but their teaching program is similar to that of the French curriculum followed by the other schools. The IBT was considered to be an excellent 
scientific dataset for teaching lessons and was aligned with a series of expected skills, which will be highlighted throughout this study.

One of the expected skills is to identify, extract and organize information from scientific data. In middle school lessons, earthquakes are taught as being the result of the Earth's internal activity. Students learn that ground motions during an earthquake are due to different waves shaking the surface. A typical class exercise is to identify different seismic phases in a seismogram. During subsequent high school lessons, a classic exercise is to determine the arrival times of seismic $\mathrm{P}$ and $\mathrm{S}$ waves in order to locate the epicenter. We were strongly convinced that the data from the IBT could be used instead of these classic exercises as a previously unseen dataset. Furthermore, it was felt that student motivation would be increased by knowing that the InSight science team would analyze their results.

At the start of this project, a training process was required to efficiently prepare students for the upcoming synthetic data analysis.

\section{Student Training Process}

\section{Real Earth and Synthetic Mars Data}

In order to train students and increase their skills in seismic signal analysis, we provided students with two newsletters in October 2017. Each document was in PDF format, with numerical data attached. In this study, all numerical datasets were analyzed with SeisGram2K80_ECOLE.jar (SG2K80, Lomax A., 2000) software. A specific velocity model was implemented by A. Lomax (from Sohn and Spohn, 1997).

The task approach was to study examples of signal processing. Students first worked on decimation and its effect on seismic data. We provided real seismograms recorded at the BLOR 
education station ("Lycée de la Montagne" high school in Valdeblore, France). The earthquakes considered were:

the April 7, 2014, Barcelonnette earthquake (Mw 4.9, France, $0.6^{\circ}$ epicentral distance);

- the April 16, 2016, earthquake (Mw 7.8, Ecuador region, 87.6 epicentral distance).

Students then worked on bandpass filtering and frequency content. We provided synthetic signals from the IBT. The proposed fictional time periods were:

- January 10 to 15,2019 ;

- July 15, 2019;

- September 22, 2019.

We rotated these signals into the north, east, and $\mathrm{Z}$ (vertical) directions from metadata provided by the IBT organizers using the ObsPy packages (Krischer et al., 2015). No instrumental correction for response was applied.

Decimation of Seismic Signals: an Exercise to Manipulate, Experiment, and Understand the Nature of the Data Used

The first exercise was designed to help students become familiar with the nature of the IBT dataset, especially with the difficulty of working with decimated seismic data. The SEIS seismometer stores data at $100 \mathrm{~Hz}$. At the time of the IBT, the initial sampling rate retained for future real data transmission was $2 \mathrm{~Hz}$. This corresponds to a volume of data transfer guaranteed by the NASA. The educational seismic stations used by students typically store ground motion at $50 \mathrm{~Hz}$. Therefore, the first exercise was to introduce the synthetic data corresponding to decimated data, i.e. with lower resolution than the raw data. Students worked 
on the Barcelonnette earthquake decimated to $2 \mathrm{~Hz}$. Decimation was carried out using the Python ObsPy software package (with an anti-aliasing low-pass filter). Figure 2a shows raw and decimated seismograms (vertical component). Change in amplitude was the first effect observed by students. They understood that samples were missing, which implies that information about ground motion was missing. Zooming in with SG2K80 also allowed them to observe changes in shape (Fig. 2b). After these first manipulations, students worked on the teleseismic event. At first they observed no significant changes in amplitude between the raw and the decimated signal (Fig. 2c). They observed that the decimation had very little effect on the signal. Zooming in enabled them to observe small differences due to the anti-aliasing prefiltering (Fig. 2d).

This first analysis of changes of seismogram shapes enabled students to understand the effect of this kind of processing on raw data. Understanding the link between the content of a dataset, and the information that can be extracted from it, is an important skill required in French educational programs. Moreover, students were also able to imagine how difficult it would be to analyze future real Martian seismograms decimated to $2 \mathrm{~Hz}$.

This first step concluded with the introduction of the relationship between the shape and period of the signal. Signals were described as being composed of tighter or looser arcs, with tight arcs corresponding to short periods and broad arcs corresponding to long periods, following the approach of Bigot-Cormier and Berenguer (2017). This allowed us to introduce a second step based on frequency analysis.

\section{Bandpass Filter and Spectrogram: Use of Digital Tools to Identify Seismic Waves}

The frequency content of seismograms was introduced in response to the question raised by students: "How will scientists be able to detect seismic activity?". For both middle and high 
school students, the use of a bandpass filter is unusual. Understanding the calculation of spectrograms is too difficult, and it is not a subject in the French curriculum. However, students are expected to use digital processing software. SG2K80 proposes tools to filter seismograms and to compute a corresponding spectrogram, which was introduced as a data processing method to highlight the frequency content of the continuous signals. To become familiar with these different aspects, students were invited to work with the synthetic seismogram on January 12, 2019 (IBT fictional day, vertical component, Fig. 3). Note that any mentions below of a synthetic seismogram refer to the IBT, except seismograms computed in the study of Bozdağ et al. (2017).

Students started this new activity by applying bandpass filters to understand their effects on the seismograms analyzed. Two frequency intervals were provided:

- from $0.001 \mathrm{~Hz}$ to $0.01 \mathrm{~Hz}$ (lf-bp for low frequencies bandpass), - $\quad$ from $0.01 \mathrm{~Hz}$ to $1.0 \mathrm{~Hz}$ (hf-bp for high frequencies bandpass).

The frequency of $1 \mathrm{~Hz}$ corresponds to the Nyquist frequency, i.e. the maximum frequency that can be analyzed for a decimation to $2 \mathrm{~Hz}$. The comparison of these three signals (raw and filtered) allowed students to highlight different points of the filtering process. By applying lfbp filtering, they observed that the very long period arc observed in Figure 3a was filtered out. They also observed a long duration event (Fig. 3b). With hf-bp filtering this long duration event was always observed along with a later and shorter duration event (Fig. 3c).

This kind of processing is consistent with the skills required by the educational curriculum. Students showed they understood that:

events (seismic, atmospheric, etc.) observed in a seismogram have their own frequency characteristics; 
- the filtering process is used to try to highlight expected or searched events in seismograms;

Although, in this case, a filtering process allows the detection of significant events, we invited

students to analyze the computed spectrogram from the raw seismogram (SG2K80 spectrogram

tool, Fig. 3d and 3e). Students observed that the long and later short events are easier to detect

by displaying the frequency content of the seismogram reading. Figure $3 \mathrm{~d}$ shows that the two ground motion.

Students understood that hidden synthetic marsquakes could be easier to detect by processing data. To go even deeper into the analysis, zooming in on the late and short event was proposed (Fig. 3e). Students observed that the long duration signal is composed of a frequency content different from the shorter duration event. They also observed an extended coma-like shape (Fig. 3e, black dashed ellipse). From discussions with seismologists at Géoazur (who also participated in the IBT as one of the challengers, Van Driel et al., 2019), this specific shape was designated as the signature of Rayleigh waves. These surface waves have a velocity that is dependent on their frequencies. Thus, some Rayleigh waves arrive earlier and some arrive later, which reflects their dispersion. This specific shape was used to determine and identify them. The frequency content of body waves was also approached. From the July 15 (M4.3) and the September 22 (M5.0) synthetic events, the frequency content of body waves was considered as ranging from $0.3 \mathrm{~Hz}$ to $0.9 \mathrm{~Hz}$ (higher than the frequency content of Rayleigh waves). The work on seismic phases with these large synthetic events was considered as sufficient to help students to detect smaller nearby quakes with higher frequency content. 
The training process stopped here for middle school students. According to their educational curriculum, they were ready to analyze synthetic data. Their goal was to identify arrival times of seismic waves and to propose their part of the School Team catalog of seismicity. It was possible to extend this analysis for high school students, thus the second newsletter was given to them.

Guided Analysis and Interpretation of Synthetic Signals from the InSight Blind Test: Skills Expected for High School Students

\section{A. Estimation of the epicentral distance based on Rayleigh wave arrival times}

Extracting information from scientific datasets is an expected skill for high school students. Locating the epicenter is a good exercise for this, and even more so if the dataset comes from a current scientific project. Typically, seismic events are located by analyzing $\mathrm{P}$ and $\mathrm{S}$ wave arrival times from three or more seismic stations. One aim of the second newsletter given to students was to introduce a location technique using only one three-component station, without any knowledge of an accurate deep structure of the planet, and without the origin time. We proposed using successive Rayleigh wave arrival times (Panning et al., 2015). Hereafter this paper will use the following notations (Fig. $4 \mathrm{a}$ and $4 \mathrm{~b}$ ):

- t1: the first arrival time of Rayleigh waves at the virtual station, i.e. the shortest surface travel time between the epicenter and the station (LR1, for Long-period Rayleigh 1);

- $\quad$ t2: the second arrival time of Rayleigh waves at the station, i.e. the longest surface travel time between the epicenter and the station (LR2); 
- t3: the third arrival time of Rayleigh waves at the station, i.e. the shortest surface travel time between the epicenter and the station, plus a complete surface trip around the planet (LR3).

The method from Roques et al. (2016) was used to illustrate this approach (Fig. S1). The synthetic seismograms used in this method came from the study by Bozdağ et al. (2017). They were computed at virtual stations along the Mars equator, spaced by $20^{\circ}$. The mathematical formula to compute epicentral distance from $\mathrm{t} 1, \mathrm{t} 2$, and $\mathrm{t} 3$ arrival times is:

$$
\text { Epicentral distance }=\frac{t 3-t 2}{t 3-t 1} * \pi * R_{\text {planet }}
$$

where $R_{\text {planet }}$ is the radius of the considered planet. Distances are in kilometers and arrival times are in seconds. This work was interesting because distances and origin times were known. Students were easily able to confirm their results.

We then invited students to work with an unknown event from the IBT using the synthetic seismogram from September 22, 2019 (Fig. 4b). We chose this event because the analysis of its frequency content showed specific signatures considered as a marker of Rayleigh waves. Students were able to observe the different wave trains in the time domain, which presented specific signatures in the frequency domain. From this analysis and by picking the three passages of Rayleigh waves, students estimated an epicenter located at $35.5^{\circ}$ from the station. Thus they understood that this approach is not enough to locate the event. They estimated a distance, but the direction was missing. This aspect was the subject of the last training exercise.

\section{B. Azimuth and back-azimuth estimation from the rotation of horizontal components}

This last exercise was introduced using a simple hands-on activity. We provided electronic accelerometers and the RISSC@ (Record Interface Sensors at School, see Data and Resources) 
interface. This educational interface displays records from each component in real time, which are identified with a sticky label (Fig. S2). The accelerometers were fixed on a table, and students followed two procedures: first, to apply an impact parallel to the table plane in the $\mathrm{X}$ direction of the device, and second, to apply an impact in the Y direction of the device. Using records displayed with RISSC, students observed the difference in amplitude of each component and concluded that the maximum amplitude is observed in the main direction of wave propagation. In class, students then reviewed the relationship between azimuth and backazimuth. SG2K80 software includes a tool to compute the angle value of the azimuth from the first $\mathrm{P}$ wave amplitude on horizontal components (Fig. 5). This function allows recomputed signals to be displayed after a chosen rotation value (as a virtual rotation of the sensor in the geographical coordinate system). Figure 5a shows the first $\mathrm{P}$ wave on each component, without rotation. Figure $5 \mathrm{~b}$ shows a flat $\mathrm{P}$ wave on the East component for a $65^{\circ}$ (clockwise) rotation. This is also the value for which the $\mathrm{P}$ wave amplitude is maximal on the North component. Students understood that this virtual rotation of the sensor allows them to determine the direction for which the first ground motion is maximal on one of the horizontal components and zero on the other.

The last training exercise involved determining the back-azimuth. From the $\mathrm{P}$ wave polarity (upwards) on the vertical component, students calculated a back-azimuth equal to $245^{\circ}$. The final catalog of the IBT was not available at the moment of this training process. Students waited for the publication of the solution to evaluate their first detection. Figure S3 shows the results of this training exercise validated after the publication of the true catalog. They used the EduCarte-Mars geographical information system (GIS) to display the results of location. The specific Mars digital field model was implemented by A. Lomax. 
This last activity completed the schools' training for the IBT. The fourteen schools then each received one month of non-overlapping synthetic data and started their analyses during their teaching sessions.

\section{Blind Test Independent Data Analysis and the Creation of the School Team Catalog}

The analysis phase started at the beginning of November, 2017, and ended in January, 2018. This period was long enough for teachers to integrate this challenge (training and analysis phases) into their official teaching hours. Students worked for six to ten hours on this project.

We now describe two activities performed by students at each school.

\section{A Daily Atmospheric Signature}

During the one-year-long synthetic seismogram, disturbances in the continuous signal were not exclusively due to traveling seismic waves. For example, environmental noise (Spiga et al. 2010) was added in order to create a signal that was as realistic as possible (Clinton et al., 2017), with the associated modeled seismic noise originating from the interaction of the environment with the lander or the ground (Murdoch et al, 2017a, 2017b, Kenda et al., 2017). See Spiga et al. (2018) for a general review of atmospheric seismic noise and Lognonné et al. (2019) for noise shielding on the SEIS instrument.

During the training steps, students identified an unknown long event in the synthetic seismogram that occurred on January 12, 2019 (fictional day from the IBT). During the analysis phase, students observed that in fact this long event occurred each day, but not at the same hour. Students asked us for an explanation of this phenomenon, and we submitted the question to a researcher, who gave them the following explanation. The sun warms the surface of Mars, 
which causes thermal agitation (convection) near the surface. At nightfall, the surface cools because the sun no longer warms it and convection stops. The wind blows, but there are no rapid turbulent fluctuations that produce this atmospheric noise. The observed time lag can be explained by the length of Martian days, which last approximately 24 hours and 39 minutes.

One of our aims was reached through this interaction, i.e. to create a link between students and researchers, and to improve the students' scientific inquiry skills.

Estimation of the Epicentral Distance of an Unknown Event That Occurred on July 15, 2019

This section presents the analysis provided by high school students of the event of July 15, 2019 (fictional day from the IBT). They were able to observe different wave trains on the vertical component and they clearly identified two Rayleigh wave signatures in the frequency domain (Fig.7). However, without a clear third signature from the whole day's seismogram, they decided to pick a third Rayleigh wave at the start of an increase of the scale amplitude around 7:00 a.m. By picking these three Rayleigh waves, they obtained an epicentral distance equal to $90.5^{\circ}$ (from the corresponding SG2K80 tool). The correct epicentral distance was $90.94^{\circ}$. The slight change in amplitude in the frequency domain is probably due to the start of daily atmospheric disturbances, but the lower value of the bandpass filter value applied by students $(0.1 \mathrm{~Hz}$ to $1 \mathrm{~Hz}$, Fig. 7) was too high to highlight this daily event. However, we appreciated their approach and their thinking through the use of the analysis processes they learned during the training phase. 
301

302

The teachers' geophysical skills enabled the project to be properly completed. They have attended various workshops on the subject during their careers and have already worked on educational projects based on seismic data. The teachers included this challenge in their teaching time and at their convenience. As mentioned above, the students worked at most about ten hours. The schools worked independently during the analysis phase. The main reason for this was that teachers chose the allocated period to work on synthetic data. At the end of January 2018, the catalog from the School Team was provided to the IBT organizers. This catalog (Table 1) was then compiled in Van Driel et al. (2019) (Fig. S4). The School Team catalog contained fifteen correct events: thirteen quakes and two impacts. Six high schools and two middle schools found these events. The other schools gave wrong detections. For the students, the main constraints were the available tools and the limited time to work on this challenge.

Detected events were located between $700 \mathrm{~km}$ and $8400 \mathrm{~km}$ from the chosen seismometer location. The detected synthetic events had magnitudes ranging from 2.5 to 5 . The closest event in the true catalog $(191 \mathrm{~km}, \mathrm{M} 2.5)$ was not detected. Two events of magnitude 2.5 and 2.6 were detected. Their epicentral locations were $724 \mathrm{~km}$ and $713 \mathrm{~km}$ respectively. Seven events, ranging from magnitude 3 to magnitude 4, were detected. Their epicentral locations ranged from $1000 \mathrm{~km}$ to $6500 \mathrm{~km}$. One event with a magnitude higher than 4 was detected (at 5379 $\mathrm{km}$ ). The larger event (M5.0, $2000 \mathrm{~km}$ ) occurred on September 22 (studied during the training process) was also added to the catalog. Two impacts were also detected, the stronger impact on October 24, and a weaker impact on October 25.

In total, 103 events were compiled in the School Team catalog. Changes in the amplitude and frequency of the continuous signal often were considered as seismic waves, because the corresponding computing spectrogram showed changes in amplitudes. These false detections could be a result of the very short teaching time allowed in the training and analysis phases. 
These many false detections could be the starting point for a new educational project with a dataset from the IBT. Future student groups could start analyzing why these false detections were made. The aim would be to improve the training phase documentation in order to facilitate the dismissal of some events in the continuous signal.

This study could be conducted once again at middle schools and high schools, which could be paired. Middle school students would work on identifying seismic waves, and the high school students would have two objectives: i) validate or invalidate detections, ii) try to estimate a location for detections considered as true. This networking would allow for an increase of educational skills. Furthermore, annual educational projects are planned in new educational programs for high schools. A longer period to work on this challenge would be useful to enable us to compare the quality of the catalog provided.

\section{Conclusion}

Of course, our ambition was not to compete with other science teams. Our main goal was to highlight the IBT dataset to school students. This objective was achieved because of motivated teachers who decided to engage their students in this challenge. No written evaluation was specifically carried out, but all teachers reported their satisfaction with the work provided by students. They were also satisfied that they had been able to include this dataset in their own activities. Figures S5a and S5b show pictures of students working on this challenge. Even the few students with learning difficulties responded well to the project, showing a good level of involvement and were engaged in class discussions. We think that the reason was that the framework was out of the ordinary. The aim was not to work on a typical exercise, but to suggest a catalog to the InSight Science Team. 
Teacher feedback focused on the great impact of the IBT on classroom dynamics. It allowed students to develop the following main skills:

- practice a scientific approach;

- demonstrate observation skills, curiosity, critical thinking;

- experience autonomy;

- communicate in scientifically appropriate language: oral, written, graphic, numerical.

Middle school students showed that they were able to detect synthetic events, even though their scientific background was less developed than that of high school students. This point highlights that involvement and seriousness, and not the age of students, were the main determining aspects to properly carry out this challenge.

The French EduMed Observatory educational project organized a seminar in the French Géoazur laboratory. Students from high schools came to present the classwork they had carried out during their school year. One group presented their work from the September 22 synthetic quake (Fig. S5c). They presented their picks of Rayleigh waves and their estimate of the epicentral location. They also presented their work on 1D velocity models proposed for the IBT (Clinton et al., 2017). They estimated the origin time from $\mathrm{t} 1$, $\mathrm{t} 2$, and $\mathrm{t} 3$, and then they calculated the velocity of the first $\mathrm{P}$ wave. They also considered the following starting models: i) a homogeneous planet, ii) the source located at the surface, iii) a seismic ray as a straight line between the source and the station. They also computed a theoretical depth reached by this first "straight" $\mathrm{P}$ wave. By comparing their results with velocity models published in Clinton et al. (2017), they understood that they had chosen a wrong starting velocity model, and learned about how seismic datasets are used to understand the deep structure of Mars. Although they did not succeed in determining the model that was used for the IBT, they showed that they developed many expected skills by working on this dataset. 
372 Student teams are now ready and looking forward to analyzing real data from Mars. In addition,

373 educators should keep in mind that even more challenging seismic signals are expected to be 374 recorded on Mars, with a majority of small, nearby marsquakes (higher frequency content, 375 lower signal noise ratio). A couple of teleseismic events will hopefully reveal the deep interior 376 of the planet.

\section{Data and Resources}

379 Seismograms from the two earthquakes recorded at the BLOR educational seismic station,

SeisGram2K80_ECOLE.jar software, and the RISSC interface are available on the EduMed

Observatory website: - the Barcelonnette earthquake:

http://edumed.unice.fr/fr/data-center/seismo/donnees-seismo/2014-04-07-5_0_barcelonnette - The Ecuador earthquake:

http://edumed.unice.fr/fr/data-center/seismo/donnees-seismo/2016-04-16-7_8_ecuador - SG2K80:

http://edumed.unice.fr/fr/contents/news/tools-lab/SeisGram2K

391 EduMed Observatory is funded by the University of Côte d'Azur - JEDI Investments in the

392 Future project managed under reference number ANR-15-IDEX-01. 
Synthetic seismograms for the IBT are available from the specific ETH website (http://blindtest.mars.ethz.ch).

The synthetic data presented in this study and EduCarte software (Mars version) are also available on the French InSight educational website supported by the Centre National d'Etudes Spatiales (CNES):

- InSight Blind Test dataset:

https://insight.oca.eu/images/InSight_Medias/zip/blindtest_daily_synthetic_data.zip

- Synthetic data from Bozdağ et al. (2017):

https://insight.oca.eu/images/InSight_Medias/zip/data/data-bozdag-2017.zip

- EduCarte Mars (@ A. Lomax and J.L. Berenguer):

https://insight.oca.eu/images/InSight_Medias/zip/software/Educarte-Mars-3.3.0X18.zip

\section{Acknowledgments}

We are especially grateful to the IBT organizers for accepting a School Team in their challenge and to have provided their dataset. We are also grateful for the help from our scientist partners: Anne Deschamps, Fabrice Peix, Jérôme Chèze (Laboratoire Géoazur), and Aymeric Spiga (Laboratoire de Météorologie Dynamique) for their help and support. InSight Education activities are supported by CNES. This is InSight contribution number: ICN 97. We also are grateful to the reviewers, and especially to Jennifer Hecker for reviewing the English language and grammar used. 


\section{References}

416

417

418

419

420

421

422

423

424

425

426

427

428

429

430

431

432

433

Bigot-Cormier Florence and Jean-Luc Berenguer (2017). How students Can Experience Science and Become Researchers: Tracking MERMAID Floats in the Oceans. Seismological Research Letters, Volume 88, Number 2A, doi:10.1785/0220160121.

Bozdağ, E., Y. Ruan, N. Metthez, A. Khan, K. Leng, M. van Driel, .., and B.W. Banerdt (2017). Simulations of Seismic Wave Propagation on Mars. Space Science Review, Volume 211, Issue 1-4, pp 571-594, doi:10.1007/s11214-017-0350-z

Clinton, J., D. Giardini, P. Lognonné, B.W. Banerdt, M. Van Driel, M. Drilleau, ..., and A. Spiga (2017). Preparing for InSight: An Invitation to Participate in a Blind Test for Martian Seismicity. Seismological Research Letters, 88.5, pp. 1290-1302, doi:10.1785/0220170094.

Courboulex, F., J.L. Berenguer, A. Tocheport, M.P Bovin, E. calais, Y. Esnault, .., and J. Virieux (2012). SISMOS à l'Ecole : A Worldwide Network of Realtime Seismometers in Schools. Seismological Research Letters, volume 83, number 5, September/October 2012, doi:10.1785/0220110139.

Kenda, B., P. Lognonné, A. Spiga, T. Kawamura, S. Kedar, W.B. Banerdt, and R. Lorenz (2017). Modeling of ground deformation and shallow surface waves generated by Martian dust, devils and perspectives for near-surface structure inversion. Space Science review, 211, 501-524, doi:10.1007/s11214-017-0378-0

Krischer, L., T. Megies, R. Barsch, M. Beyreuther, T. Lecocq, C. Caudron, and J. Wassermann (2015). ObsPy: a bridge for seismology into the scientific Python ecosystem. Computational Science \& Discovery 8 (2015) 014003, doi:10.1088/1749$4699 / 8 / 1 / 014003$ 
Lomax Anthony (2000). The Orfeus Java Workshop: Distributed Computing in Earthquake Seismology. Seismological Research Letters, Volume 71, Number 5, doi: 10.1785/gssrl.71.5.589

Lognonné, P., W.B. Banerdt, D. Giardini, W.T. Pike, U. Christensen, P. Laudet, ..., and J.Wookey (2019). SEIS: Insight's Seismic Experiment for Internal Structure of Mars. Space Science Reviews, 215:12, doi.org/10.1007/s11214-018-0574-6

Murdoch, N., D. Mimoun, R.F. Garcia, W. Rapin, T. Kawamura, P. Lognonné, ... , and W.B Banerdt (2017A?). Evaluating the Wind-Induced Mechanical Noise on the InSight Seismometers. Space Science Reviews, 211(1-4), 429-455, doi.org/10.1007/s11214016-0311-y

Murdoch, N., B. Kenda, T. Kawamura, A. Spiga, P. Lognonné, D. Mimoun, and W.B. Banerdt (2017B?). Estimations of the seismic pressure noise on Mars determined from Large Eddy Simulations and demonstration of pressure decorrelation techniques for the InSight mission. Space Science Reviews, 211,457-483, doi:10.1007/s11214-017-0343-

Panning, M. P., E. Beucler, M. Drilleau, A. Mocquet, P. Lognonné, and W.B. Banerdt (2015). Verifying single-station seismic approaches using Earth-based data: Preparation for data return from the InSight mission to Mars. Icarus, 248, 230-242. doi.org/10.1016/j.icarus.2014.10.035

Roques A., J.L. Berenguer, and E. Bozdağ (2016). A single geophone to locate seismic events on Mars. EGU General Assembly 2016, held 17-22 April, 2016 in Vienna Austria ,id. EPSC2016-5313 
Spiga, A., F. Forget, S.R. Lewis, and D.P. Hinson (2010). Structure and dynamics of the convective boundary layer on mars as inferred from large-eddy simulations and remotesensing measurements. Q. J. R. Meteorol. Soc. 136, 414-428, doi.org/10.1002/qj.563

Spiga, A., D. Banfield, N.A. Teanby, F. Forget, A. Lucas, B. Kenda (2018). Atmospheric Science with InSight. Space Science Reviews, 214:109, doi.org/10.1007/s11214-0180543-0

Sohn, F., and T. Spohn (1997). The interior structure of Mars: Implications from SNC meteorites. Journal of Geophysical Research, Volume 102, Numero E1, pages 16131635

Van Driel M., S. Ceylan, J.F. Clinton, D. Giardini, H. Alemany, A. Allam, ..., and Y. Zheng (2019). Preparing for InSight: Evaluation of the Blind Test for Martian Seismicity. Seismological Research Letters, doi.org/10.1785/0220180379

Zollo, A., A. Bobbio, J.L. Berenguer, F. Courboulex, P. Denton, G. Festa, ..., and D. Giardini (2014). The European Experience of Educational Seismology. In: Tong V. (eds) Geoscience Research and Outreach. Innovations in Science Education and Technology, vol 21. Springer, Dordrecht. 
483 Julien Balestra: julien.balestra@univ-cotedazur.fr

484 David Ambrois: david.ambrois@geoazur.unice.fr

485 Jean-Luc Berenguer: Jean-Luc.Berenguer@unice.fr

486 Florence Bigot-Cormier: florence.bigot-cormier@lyceeshanghai.com

487 Françoise Courboulex: courboulex@geoazur.unice.fr

488 Philippe Lognonné: lognonne@ipgp.fr

489 Lucie Rolland: lrolland@ geoazur.unice.fr

490 Martin Van Driel: vandriel@erdw.ethz.ch

491

492

493

494

495

496

497

498

499

500

501 
Correct quake detections

\begin{tabular}{|c|c|c|}
\hline date & epicentral distance $(\mathrm{km})$ & magnitude \\
\hline 2019-01-12 20:23:50.66 & 3026.5 & 3.8 \\
\hline 2019-01-29 00:21:07.83 & 2630.0 & 2.9 \\
\hline 2019-07-15 04:14:57.37 & 5379.6 & 4.3 \\
\hline 2019-07-20 22:26:35.77 & 1274.7 & 3.6 \\
\hline 2019-07-30 00:34:15.52 & 1337.0 & 3.0 \\
\hline 2019-09-03 12:30:52.88 & 1042.8 & 3.0 \\
\hline 2019-09-22 00:41:02.23 & 2082.7 & 5.0 \\
\hline 2019-10-06 04:19:50.47 & 713.7 & 2.6 \\
\hline 2019-10-24 01:53:56.71 & 724.6 & 2.5 \\
\hline 2019-11-02 01:21:15.37 & 3051.0 & 3.0 \\
\hline 2019-11-09 05:50:32.50 & 3703.6 & 2.9 \\
\hline 2019-11-17 00:25:25.91 & 4006.5 & 3.3 \\
\hline 2019-11-22 11:41:49.10 & 6486.5 & 3.6 \\
\hline \multicolumn{3}{|l|}{ Correct impact detections } \\
\hline date & epicentral distance $(\mathrm{km})$ & mass $(\mathrm{kg})$ \\
\hline $2019-10-24$ 22:45:52 & 997.1 & 6484.7 \\
\hline 2019-10-25 00:58:47 & 4245.4 & 637.7 \\
\hline
\end{tabular}

503 Table 1. Correct detections from the School Team (Van Driel et al., 2019).

504

505

506

507 


\section{List of Figure Captions}

509

510

511

512

513

514

515

516

517

518

519

520

521

522

523

524

525

526

527

528

529

530

Figure 1. Map of the School Team. (a) Global view. (b) An enlargement of European Schools. (c) An enlargement of Caribbean Schools (French and Haïtian). White diamonds: location marker.

Figure 2. The April 7, 2014, Mw 4.9 Barcelonnette ((a) and (b)) and the April 16, 2016, Mw 7.8 Ecuadorian region earthquakes ((c) and (d)) recorded at the BLOR educational station (southeastern France, epicentral distances of $0.6^{\circ}$ and $87.6^{\circ}$ respectively). (a) Upper seismogram: raw vertical component signal $(50 \mathrm{~Hz}$ sampling rate). Lower seismogram: raw signal decimated to $2 \mathrm{~Hz}$. (b) An enlargement of the starting record of the earthquake from (a). Note that the amplitude scale for the decimated signal is ten times smaller than the scale for the raw signal. (c) Upper seismogram: raw vertical component signal (50Hz sampling rate). Lower seismogram: raw signal decimated to $2 \mathrm{~Hz}$. (d) An enlargement of the starting record of the earthquake from (c). SR: sampling rate.

Figure 3. Synthetic marsquake on January 12, 2019 (vertical component). (a) Raw seismogram. (b) Raw seismogram filtered with bandpass filtering from $0.001 \mathrm{~Hz}$ to $0.01 \mathrm{~Hz}$. (c) Raw seismogram filtered with bandpass filtering from $0.01 \mathrm{~Hz}$ to $1.0 \mathrm{~Hz}$. (d) Raw seismogram and corresponding spectrogram. (e) An enlargement of the black dashed rectangle in (d). Black dashed ellipse: supposed frequency signature of Rayleigh waves.

Figure 4. Elements for the epicenter location from Rayleigh waves. a) Scheme of the three surface paths corresponding to the $\mathrm{t} 1, \mathrm{t} 2$, and $\mathrm{t} 3$ arrival times in $\mathrm{b}$ ). Gray star: surface seismic 
source. Gray inverted triangle: seismic station. b) Raw synthetic seismogram and corresponding spectrogram on September 22, 2019 (vertical component). This picture comes from a screenshot with SG2K80. LR1, LR2 and LR3: pick of the Rayleigh wave passage at the station. t1, t2, t3: corresponding arrival times.

Figure 5. Back-azimuth estimation for the event on September 22, 2019. (a) An enlargement of the first $\mathrm{P}$ waves on each component, without rotation. (b) New amplitudes computed from a rotation of $65^{\circ}$ clockwise. a) and b) are screenshots from SG2K80. E: east component. N: north component. Z: vertical component. (c) Relationships between P wave amplitudes from the three components, azimuth and back-azimuth direction. Azimuth: direction of the first ground motion with $180^{\circ}$ ambiguity. Back-azimuth: true direction of the first ground motion determined from the $\mathrm{P}$ wave polarity on the vertical component.

Figure 6. Synthetic seismograms from January 10 to January 15, 2019, compiled by a group of students. Vertical black lines: start of a new terrestrial day. Vertical black dashed lines: start of a new martian sol. Double arrows with black dashed vertical segments: marker of the lag between midnight (UTC) and the start of the middle daily event on January 10, 2019. From January 11 to January 15, students observed that the lag increased day after day. E: East component. N: North component. Z: vertical component.

Figure 7. Study of the unknown event detected by students on July 15, 2019. Raw seismogram filtered with bandpass values from $0.1 \mathrm{~Hz}$ to $1.0 \mathrm{~Hz}$ and the corresponding spectrogram. Vertical black lines: pick of Rayleigh waves clearly identified in the spectrogram. Vertical black dashed line: pick of LR3 hypothesized by students. 

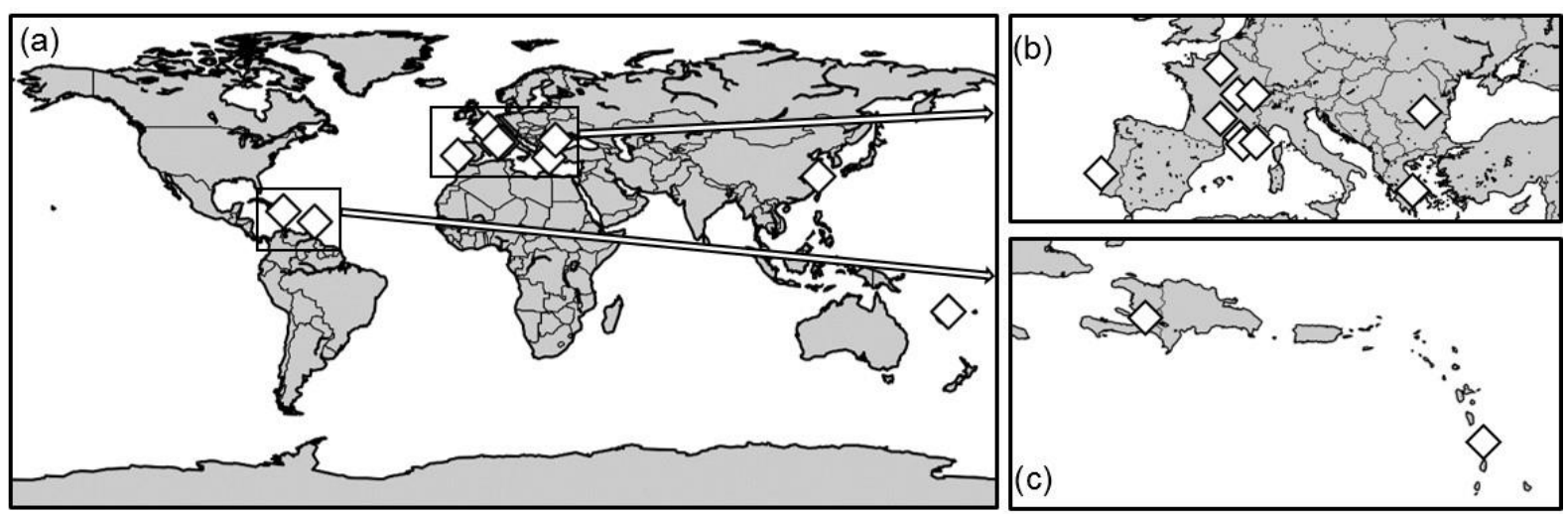

Figure 1. Map of the School Team. (a) Global view. (b) An enlargement of European Schools.

(c) An enlargement of Caribbean Schools (French and Haitian). White diamonds: location marker. 
a)
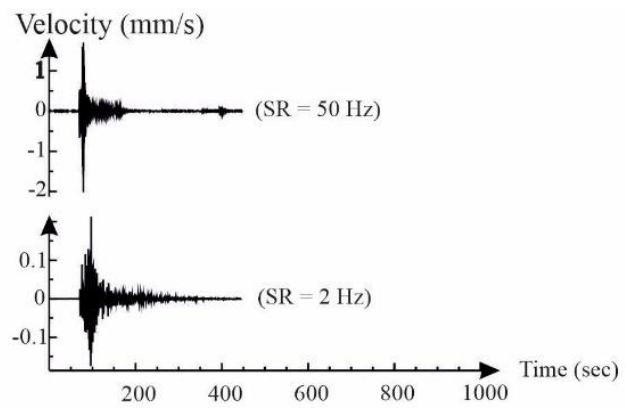

c)

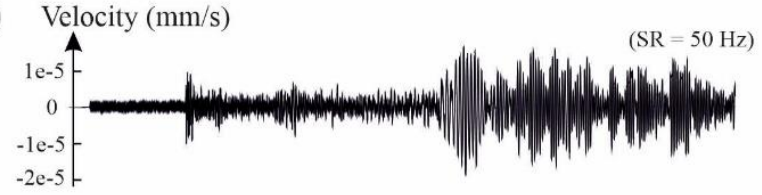

565

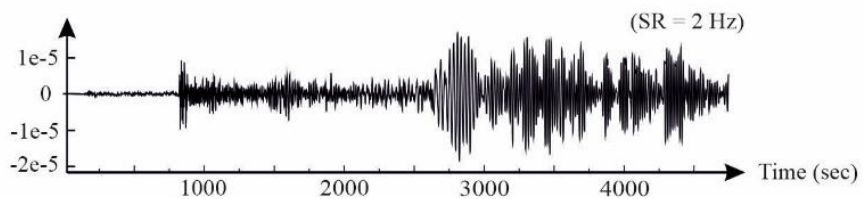

b) Velocity $(\mathrm{mm} / \mathrm{s})$
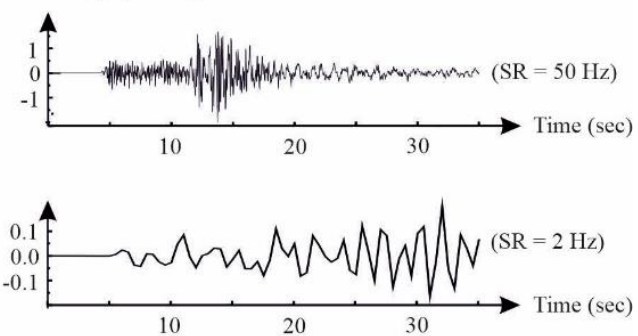

d) Velocity $(\mathrm{mm} / \mathrm{s})$
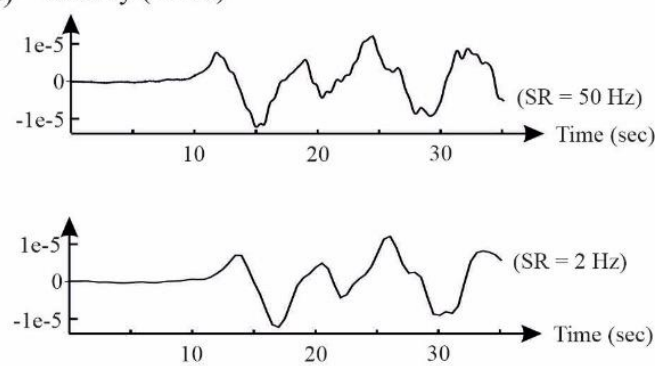

Figure 2. The April 7, 2014, Mw 4.9 Barcelonnette ((a) and (b)) and the April 16, 2016, Mw

7.8 Ecuadorian region earthquakes ((c) and (d)) recorded at the BLOR educational station

568 (southeastern France, epicentral distances of $0.6^{\circ}$ and $87.6^{\circ}$ respectively). (a) Upper

569 seismogram: raw vertical component signal (50Hz sampling rate). Lower seismogram: raw signal decimated to $2 \mathrm{~Hz}$. (b) An enlargement of the starting record of the earthquake from (a).

571 Note that the amplitude scale for the decimated signal is ten times smaller than the scale for the

572 raw signal. (c) Upper seismogram: raw vertical component signal (50Hz sampling rate). Lower

573 seismogram: raw signal decimated to $2 \mathrm{~Hz}$. (d) An enlargement of the starting record of the 574 earthquake from (c). SR: sampling rate. 


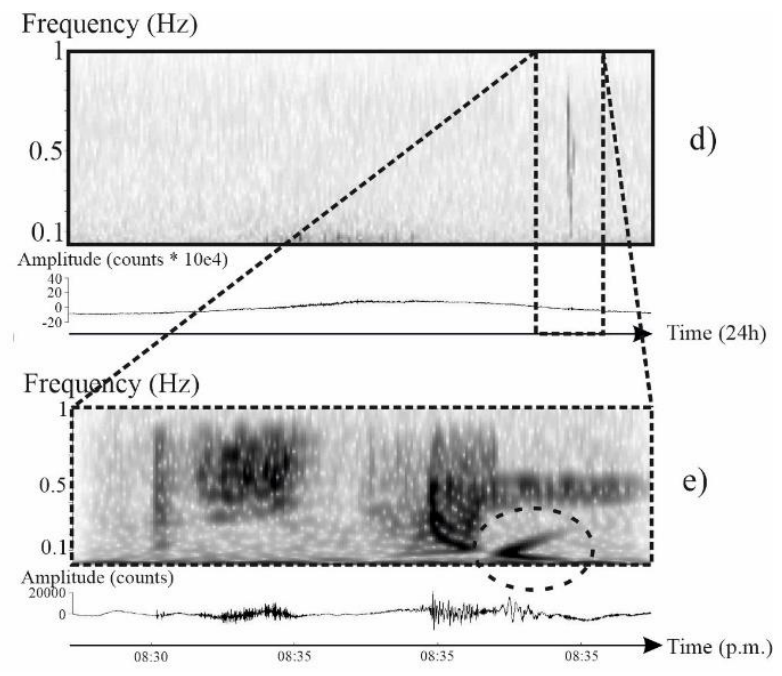

577 Figure 3. Synthetic marsquake on January 12, 2019 (vertical component). (a) Raw seismogram. (b) Raw seismogram filtered with bandpass filtering from $0.001 \mathrm{~Hz}$ to $0.01 \mathrm{~Hz}$. (c) Raw 579 seismogram filtered with bandpass filtering from $0.01 \mathrm{~Hz}$ to $1.0 \mathrm{~Hz}$. (d) Raw seismogram and 580 corresponding spectrogram. (e) An enlargement of the black dashed rectangle in (d). Black 581 dashed ellipse: supposed frequency signature of Rayleigh waves. 

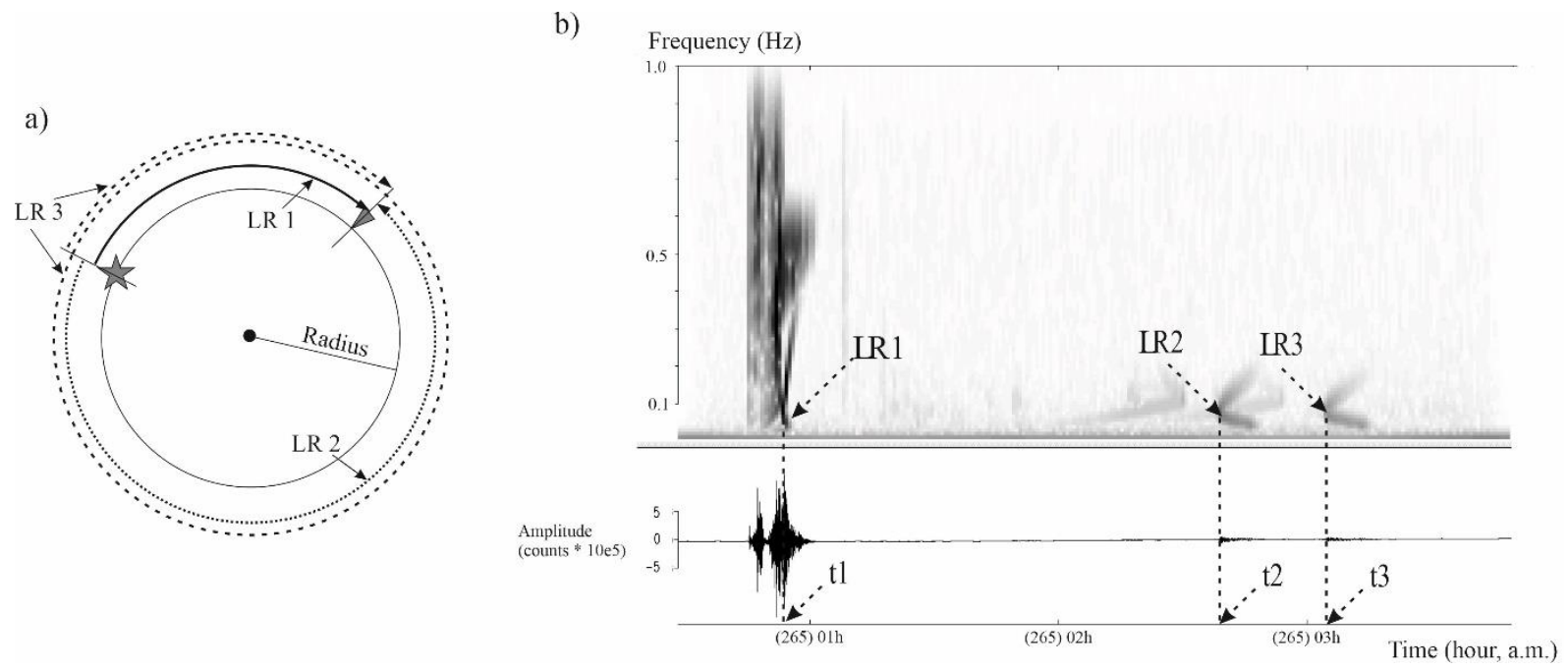

588 Figure 4. Elements for the epicenter location from Rayleigh waves. a) Scheme of the three 589 surface paths corresponding to the $\mathrm{t} 1, \mathrm{t} 2$, and $\mathrm{t} 3$ arrival times in $\mathrm{b}$ ). Gray star: surface seismic 590 source. Gray inverted triangle: seismic station. b) Raw synthetic seismogram and corresponding 591 spectrogram on September 22, 2019 (vertical component). This picture comes from a screenshot 592 with SG2K80. LR1, LR2 and LR3: pick of Rayleigh wave passage at the station. t1, t2, t3: 593 corresponding arrival times.

594

595 
a)

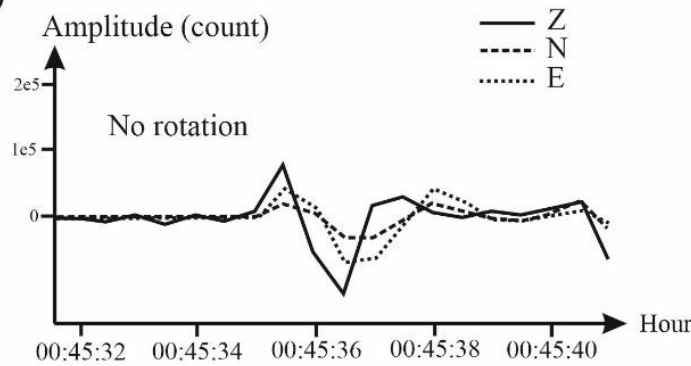

b)

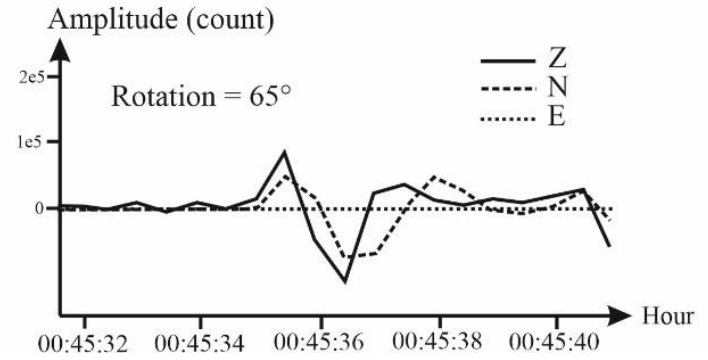

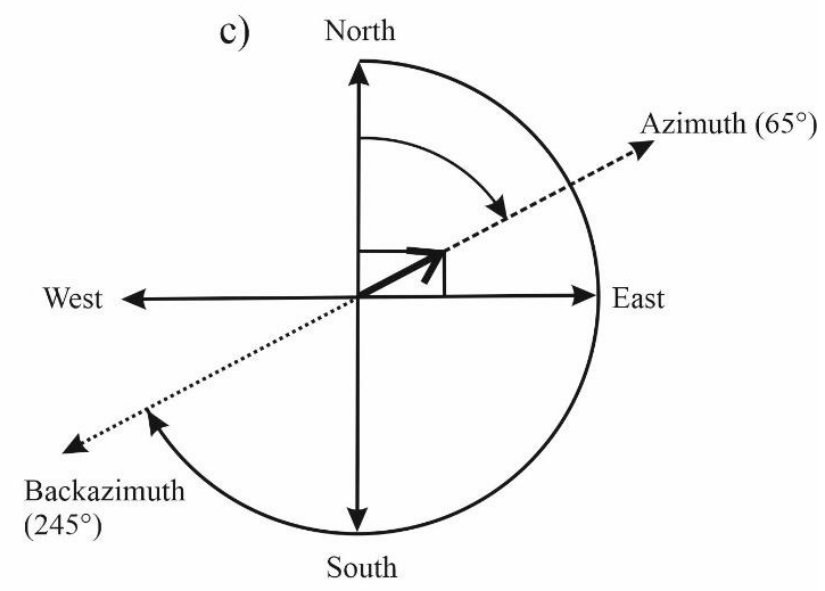

598 Figure 5. Back-azimuth estimation for the event on September 22, 2019. (a) An enlargement of 599 the first $\mathrm{P}$ waves on each component, without rotation. (b) New amplitudes computed from a 600 rotation of $65^{\circ}$ clockwise. a) and b) are screenshots from SG2K80. E: east component. N: north

601

602

603 604 605 component. Z: vertical component. (c) Relationships between P wave amplitudes from the three components, azimuth and back-azimuth direction. Azimuth: direction of the first ground motion with $180^{\circ}$ ambiguity. Back-azimuth: true direction of the first ground motion determined from the $\mathrm{P}$ wave polarity on the vertical component. 


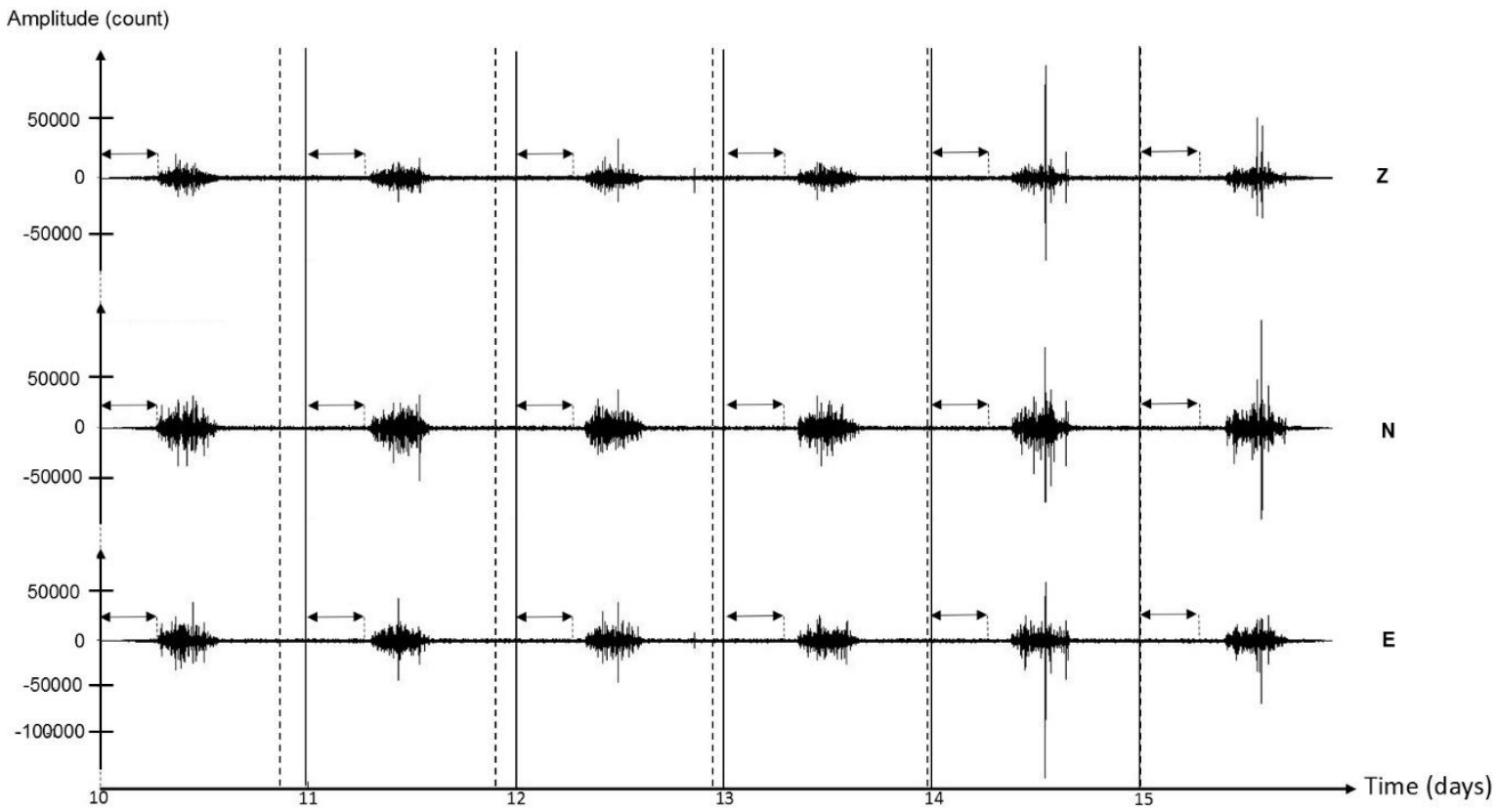

607 Figure 6. Synthetic seismograms from January 10 to January 15, 2019, compiled by a group of students. Vertical black lines: start of a new terrestrial day. Vertical black dashed lines: start of 609 a new martian sol. Double arrows with black dashed vertical segments: marker of the lag 610 between midnight (UTC) and the start of the middle daily event on January 10, 2019. From 611 January 11 to January 15, students observed that the lag increased day after day. E: East component. N: North component. Z: vertical component. 


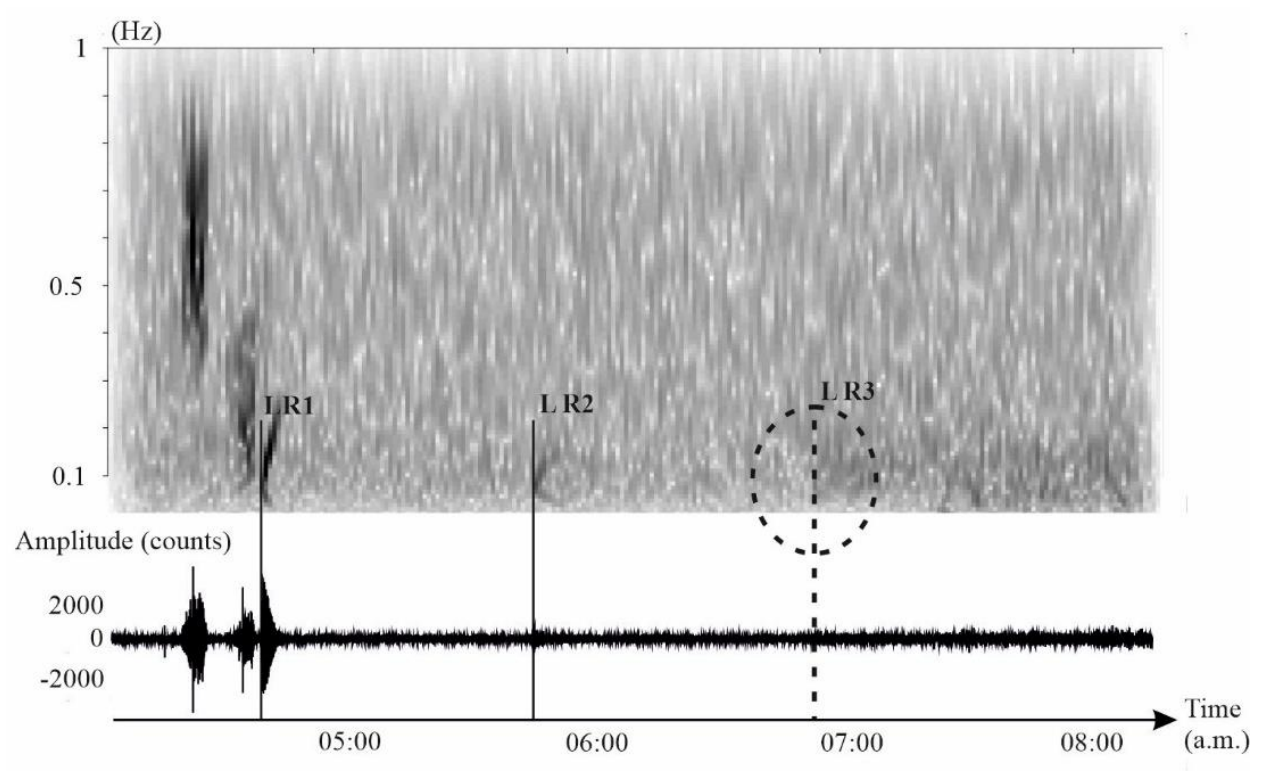

616 Figure 7. Study of the unknown event detected by students on July 15, 2019. Raw seismogram

617 filtered with bandpass values from $0.1 \mathrm{~Hz}$ to $1.0 \mathrm{~Hz}$ and the corresponding spectrogram.

618 Vertical black lines: pick of Rayleigh waves clearly identified in the spectrogram. Vertical black

619 dashed line: pick of LR3 hypothesized by students. 